\title{
Research on Supply Chain Governance Strategy: game value analysis based on Incomplete Contract Theory
}

\author{
Luyao Wang ${ }^{1, *}$ \\ ${ }^{1}$ Business School of Henan University, Kaifeng, China
}

\begin{abstract}
There are potential opportunistic risks in the partnerships of enterprises in different industries. Asymmetric information, incomplete decision-making and Human bounded rationality are factors for the formation of opportunistic risks, and adopting external governance is a feasible way to defuse the risks. Supply chain governance is a new type of governance which is different from enterprise governance. Its scope of governance is wider than enterprise governance. It is the performance of environmental evolution and organizational innovation. Based on the incomplete contract, this paper analyzes the game between the supplier and the manufacturer. It is found that in the process of the game, the cooperation benefits of both parties are the largest and the distribution of benefits is the fairest. Therefore, combined with the theory of supply chain governance, this paper hopes to maximize the value of supply chain by optimizing the supply chain governance strategy under the condition of incomplete contract.
\end{abstract}

\section{Introduction}

Edgeworth (1897) described the Pareto optimal short-term contract portfolio under the Walrasian general equilibrium by Edgeworth model in his pure theory of monopoly. After this scholars introduced uncertainty and used this model to explain the Pareto optimal long-term contract portfolio under the general equilibrium. However, no matter whether the uncertainty is introduced or not, the information between the parties analyzed by the model is symmetrical. Once it is divorced from the assumption of perfect market, such as under asymmetric information, the long-term contract may not be reached. The phenomenon of asymmetric information and incomplete decisionmaking in supply chain is especially common.

The supply chain starts with the suppliers providing raw materials, then the manufacturers making intermediate products, and the products are sent to the consumers through the distributors. In this process, the enterprises bring their upstream and downstream partners into a cooperation chain by controlling the information flow, logistics and capital flow. At present, the main body of market competition has changed from the competition between enterprises to the competition between supply chains. The supply chain management is around the core enterprise, with the goal of customer demand, which combines the functions of the enterprises in the supply chain organically and coordinates the ability of the enterprises in the supply chain, in order to maximize the overall interests of the members of the supply chain. However, in the process of enterprise cooperation, the information asymmetry makes the status of enterprises in the supply chain differences, so enterprises need to strengthen the management of supply chain partners through effective governance means. Therefore, it is necessary to study the supply chain governance. Based on incomplete contract theory and supply chain governance theory, this paper analyzes the game problem of twoechelon supply chain composed of suppliers and manufacturers.

\section{An overview of incomplete contract theory and supply chain governance theory}

\subsection{Incomplete contract theory}

Incomplete contract theory develops from contract theory. Contract theory, also called agency theory, mainly studies the economic behavior and results of different partners in a specific trading environment. It mainly includes two core issues: one is income transfer under asymmetric information, and the other is risk sharing between parties who with different risk attitudes. The theory holds that the partner has a neutral risk attitude, and the long-term contract is better than the short-term contract in encouraging both parties to improve asset specificity, but it does not explain why the long-term contract does not replace the short-term contract. With the development of theory, economists gradually realize that the contract is incomplete because of the limited rationality of the contractor or the existence of transaction cost. Coase(1937) pointed out that due to the unpredictable future, when signing a long-term contract for the supply of goods or services, it is impossible and inappropriate for the buyer to stipulate the responsibilities and obligations for the supply

*e-mail: wly1995xx@163.com 
of goods[1]. Based on the above analysis, we believe that the incomplete contract theory means that due to people's limited rationality, information asymmetry and transaction uncertainty, it is impossible to conclude a complete contract because the cost of clarifying all the terms in the contract is too high.

\subsection{Supply chain governance theory}

The concept of "governance" enter our vision is through the scholars' research of enterprise governance. The environment is becoming more and more complex and with the continuous optimization of the organizational form, the study of governance has gradually expanded from the enterprise organization layer to the network organization layer. The formation of supply chain governance is based on the continuous development of enterprise governance by combining the characteristics of supply chain and the bounded rationality of enterprise decision-makers. The academic definition of supply chain governance can be roughly divided into three categories: the first category is to divide governance into a branch of management, and think that supply chain governance is a favorable factor for the internal and external integration of supply chain; the second category is to regard supply chain governance as the governance of supply chain structure; the third category is to regard supply chain governance as a mechanism to maintain and coordinate the relationship between the core enterprises in the supply chain. This paper mainly adopts the last definition of supply chain governance, and considers that supply chain governance is the maintenance of the relationship between the upstream and downstream partners of the enterprises in the supply chain, as well as the allocation of the risks brought by market uncertainty. The core enterprises pay more attention to the maximization of the overall benefits of the enterprises in the supply chain.

At present, the academic research on supply chain governance is mostly based on transaction cost theory and trust theory. In the book capitalist economic system, Williamson (1985) holds that asset specificity, transaction frequency and uncertainty are the most direct causes of transaction costs. Based on this, he proposes that supply chain governance can be carried out through three transaction coordination modes: market system, bureaucratic system or mixed system, and constructs the basic research framework of supply chain governance. Williamson (2008) pointed out that supply chain governance is to deal with opportunism in the supply chain, so supply chain governance is further divided into market governance, bureaucratic governance and network governance[4]. Most of the later scholars divide and study the supply chain governance on this basis. At present, the more unified division of academic circles comes from Gereffi (2005), who divides supply chain governance into five modes, namely market governance, modular governance, relationship governance, leadership governance and bureaucratic governance[3]. Based on the division of supply chain governance mode by gerefi (2005), combined with the research of asset specificity and transaction cost in incomplete contract, this paper analyzes the governance strategies of manufacturer to supplier in secondary supply chain, including market-oriented governance strategy, modular governance strategy, relational governance strategy, leadership governance strategy and hierarchical governance strategy.

\subsection{Supply chain governance under Incomplete Contract Theory}

The supply chain is composed of enterprises with different division of labor and different functions. The enterprises in the supply chain make decisions independently and dispersedly. Therefore, the enterprise decision-makers will pursue the maximization of their own interests under the limited rational attitude. Due to the mutual independence between enterprises in the supply chain, the phenomenon of information asymmetry occurs. Enterprises usually retain some private information in the cooperation, which leads to that each enterprise in the supply chain has more or less "private information" that other members do not know. Because of the existence of private information, the two parties will sign an ineffective contract. The effectiveness of the contract will make both parties at risk of being damaged by opportunism. At the same time, the decision-maker's limited rationality makes it impossible for the decision-maker to accurately predict the complex environment, and it is even more impossible for the two parties to sign a binding contract. However, in order to obtain the maximum transaction efficiency under the incomplete contractual relationship, both parties will agree some solutions and methods in advance in most cases, so as to do a good job in the quasi rent distribution after the event. For example, all parties will make rules to deal with unforeseen situations. The process of making and implementing these rules is corporate governance, and the way, method and system design enterprises choose to achieve the ultimate goal is governance mechanism.

Because of the "private information" and the limited rationality of decision makers, the enterprises in the supply chain will cause opportunistic behavior and conflicting objectives among the enterprises that cooperate with each other in the supply chain, which will cause the damage of the enterprise interests and bear the transaction risk. However, as an open organization, supply chain has a small binding force, which requires enterprises to participate in its supply chain governance. Through the continuity of inter enterprise governance, the supply chain members' objectives are consistent, and the members can classify the interests together to maximize the overall benefits of the supply chain.

\section{Game Analysis between suppliers and manufacturers}

The game and cooperation between suppliers and manufacturers is the main problem of competition and cooperation in the supply chain. By studying the game between enterprises, we can understand the influence of the choice of cooperation and non cooperation between enterprises at different levels of the supply chain on the development of the supply chain. Therefore, this paper 
analyzes the cooperative game and non cooperative supply chain between suppliers and manufacturers Chain value distribution.

We establish a game model of the secondary supply chain by the supplier and the manufacturer, and make the following assumption: the two sides of the game are suppliers and manufacturers. The behavior strategy of both parties of the game is to choose "cooperation" or "not to cooperate" for suppliers and manufacturers, then the strategy space is (cooperation, non cooperation). If the supplier and manufacturer choose to cooperate, an excess positive return $\mathrm{P}$ and $\mathrm{Q}$ will be generated. Traditional theory holds that enterprises will choose information isolation and gain advantages in competition, and enterprises are reluctant to share information with other enterprises. But in the supply chain, upstream and downstream enterprises choose certain information sharing, and reduce the cost of acquiring information by acquiring the information shared by other enterprises, so that both suppliers and manufacturers will get positive benefits W. However, if one party chooses to cooperate and the other party chooses not to cooperate, the party that takes the cooperation cannot obtain the benefit of cooperation, but also pays the $\operatorname{cost} \mathrm{M}(\mathrm{M}<\mathrm{W})$ for collecting information. However, the party that takes the non cooperation will obtain the benefit of sharing information of the other party $\mathrm{W}$ and the benefit $\mathrm{V}$ of its own exclusive information. Finally, if neither of them share information with each other and pay the search cost $M$, we can get the game matrix of the following cooperative benefits:

Table1. Game matrix

\begin{tabular}{|c|c|c|c|}
\hline & \multicolumn{2}{|c|}{ Supplier } \\
\hline & & cooperation & No cooperation \\
\hline \multirow{2}{*}{ Manufacturer } & cooperation & $\mathrm{P}+\mathrm{A}, \mathrm{Q}+\mathrm{A}$ & $-\mathrm{M}, \mathrm{W}+\mathrm{V}-\mathrm{M}$ \\
\hline & No cooperation & $\mathrm{W}+\mathrm{V}-\mathrm{M},-\mathrm{M}$ & $-\mathrm{M},-\mathrm{M}$ \\
\hline
\end{tabular}

The Nash equilibrium of the two-level supply chain cooperation game is (cooperation, cooperation) and (non cooperation, non cooperation), but the income of both sides (cooperation, cooperation) is greater than (non cooperation, non cooperation). Therefore, joint cooperation is the best choice for suppliers and manufacturers, which is also an important driving force for the development of the supply chain. The above game only shows that the cooperation between supply and demand is conducive to the increase of the overall interests, but how to allocate the increased part effectively? If the final distribution of interests is unfair or unscientific, it will lead to the failure of cooperation between the two sides of the supply chain, or even the rupture of the supply chain. The cooperation between supply and demand is the premise of supply chain development, and the reasonable classification of interests is the basis of ensuring the stable development of supply chain. In the process of cooperation between the supplier and the supplier, the pricing of products or services is generally decided by the downstream manufacturers of the supply chain. The manufacturer's profit comes from the market price of the products and the wholesale price agreed with the wholesalers, while the supplier's profit mainly comes from the difference between the wholesale price and its own cost. Therefore, it is very important for the supplier and the manufacturer to determine the wholesale price. This paper will determine the wholesale price based on the cooperative game method, in order to determine a reasonable wholesale price, so as to guide enterprises to formulate their governance strategies.

\section{Analysis of manufacturer's governance strategy}

\subsection{Market oriented governance strategy}

By analyzing the maximum profit of supplier and manufacturer in non cooperative game and cooperative game, we can find that the price affects the profit distribution of both sides, and the profit distribution is the basis of the cooperation between both sides. Therefore, both supply and demand sides need to participate in the price setting to ensure the long-term cooperation. When combing and summarizing the supply chain governance mode, for different governance modes, the degree of participation in price setting and benefit distribution of enterprises in the supply chain will be different. When enterprises adopt market-oriented governance strategy, enterprises in the supply chain are driven by profits, and they will trade through equal market-oriented behavior. Williamson (1979) proposed that market-oriented governance is the main way of governance under uncertain transaction, whether it is one transaction or repeated transaction[2]. Under the market-oriented governance mode, the activities of enterprises in the supply chain are relatively independent, and the decision-making is independent. The adjustment of the relationship between cooperative enterprises will rely on the loose market mechanism. Because each enterprise in the supply chain pursues the maximization of its own interests, and the degree of information sharing among enterprises is the lowest, conflicts will occur frequently in the supply chain and among enterprises. The market belongs to the spontaneous coordination mechanism, the market transaction involves a limited number of participants, so the enterprises will not establish a strong relationship, the trust between enterprises is limited, only the price determines the production and transaction. For example, manufacturing enterprises will not let suppliers participate in product design too much, and will not empower suppliers, which is the most relaxed way of governance for manufacturing enterprises.

\subsection{Modular governance strategy}

When the enterprise adopts the modular governance strategy, the enterprise will entrust some processing tasks of the products to the competent supplier, which has lower production cost and can bring more value to the manufacturer. The enterprises adopting modular governance strategy do not worry about the risks brought 
by the deepening of cooperation. Sanchez (2015) proposed that enterprises can ensure the stability of the whole supply chain operation by removing the low efficiency production modules and finding new high efficiency production modules in the process of modular governance[5]. Therefore, the information sharing degree between enterprises adopting modular governance strategy is not high . In this mode, suppliers and manufacturing enterprises are a loose coupling relationship, and the transaction cost of changing the current cooperation is relatively low. Compared with market-oriented governance strategy, the enterprises adopting modular governance strategy will make strict restrictions on the risk division and benefit distribution. The cooperation between the two sides is closer than market-oriented governance, but it will still leave enterprises with greater "escape" opportunities. Therefore, the enterprise should be able to identify the supplier capability accurately, or to empower and guide it to reduce the loss caused by the enterprise "escaping".

\subsection{Relationship Governance Strategy}

The Enterprises adopting relationship governance strategy mean that they will work together to promote the realization of the overall goal of the supply chain and maximize the overall interests of the supply chain. The relationship governance will make the relationship between enterprises in the supply chain beyond the organizational boundary constraints, build a cooperation network together, and reach transactions through the mutual benefit actions among the members of the cooperation network. There are no clear rules of market governance and no hierarchical system of modelism in the cooperation network. Relational governance strategy means that all parties can share benefits and risks, and will adjust with the changing environment. Enterprises adopting relational governance strategy will trust their partners more, and the relationship means more profound strategic coupling. Both parties can further share information, and the asset specific investment will continue to improve. The strong party in the relationship can invest in the growth of the other party, so as to maintain the more sustainable development of both parties. $\mathrm{Wu}$ Dong Wu (2019) pointed out that enterprises need to fully consider the role of specific complementary assets in business model design, and pay more attention to the role of social and non economic factors such as relationship type, so as to achieve more sustainable development[6].

\subsection{Leadership governance strategy}

The leading governance strategy is mainly in the core enterprises of the supply chain, especially when small manufacturers are attached to large ones, the governance strategies adopted by large-scale manufacturers to small enterprises are mostly leadership governance strategies. Large manufacturers have strong supervision and control over small manufacturers, and small manufacturers have a high dependence on the purchase of large manufacturers. Therefore, in a sense, large-scale manufacturers have strong guidance on the pricing of products or services provided by small manufacturers, and affect their profit distribution. In this case, small manufacturers will become very transparent, large manufacturers can master the progress of small manufacturers, but it does not mean that large manufacturers can replace the manufacturers at will, for both sides, there will be a high conversion cost. In the leading supply chain governance strategy, the key links of the supply chain are controlled by the core enterprises of the supply chain. Some auxiliary links will be distributed to the supporting enterprises in the form of external delegation, which makes the whole supply chain structure express as the tight and dense structure around the core enterprises. The enterprises adopting this strategy can make their operation activities more planned and orderly. Through the reform of governance strategy, enterprises often pay more attention to the planning, and achieve the goals through organization and control. In this process, information transmission speed is faster and the decisions among enterprises are highly consistent.

\subsection{Bureaucratic governance strategy}

The enterprises adopting the hierarchical governance strategy are the direct equity control over some operation links in the supply chain, and the main form is management control. For example, the company flows from the parent company to the subsidiary through the establishment of standard headquarters, which is a kind of internal governance mode. When the specialization of tasks among enterprises is very high and the business is interdependent, enterprises take such governance strategies. Through this governance strategy, enterprises can obtain some of the benefits of products or services in the process of circulation based on the distribution of property rights income. At the same time, the enterprise will seek more benefits to encourage both sides to plan the future development strategy and action together.

\section{Conclusion}

In the case of incomplete contract, through the analysis of different governance strategies, we can see that the market-oriented governance strategy has the highest information asymmetry, larger cognitive bias, decentralized decision-making power and the least close relationship among enterprises. However, under this governance strategy, enterprises will have higher conversion costs because of higher dependence. Relational governance strategy is the most effective governance strategy when enterprises choose cooperation. Under relational governance, enterprises work together with reputation, friendship, interdependence and altruism to maximize the overall interests of the supply chain. Each governance strategy has its own advantages and disadvantages. At the same time, this paper can explain the factors that affect the signing of long-term contracts among enterprises to a certain extent. The closer the relationship between enterprises is, the more it can promote the signing of long-term contracts. However this paper failed to analyze the better governance strategies in 
different game situations, which is also the next research direction of this paper. We will study the matching of game and governance strategies for different game strategies. Competition and cooperation in supply chain caused by incomplete contract is common. It is impossible for contract to restrict the change of environment. Therefore, it is necessary to adopt different governance strategies according to different development stages of enterprises. Generally speaking, the choice of different corporate governance strategies has a great impact on business scale, scope and performance.

At present, most enterprises in China have the awareness and action of maintaining the supply chain, and gradually realize the importance of supply chain reform. However, the uneven distribution of interests in different links makes the supply chain have certain risks and cannot be maintained for a long time. Therefore, it is necessary to maintain the relationship between enterprises through appropriate governance, promote the rational distribution of interests among the main bodies in the supply chain, and then maintain the stable operation of the supply chain.

\section{References}

1. Coase R H . The Nature of the Firm[J]. Economica, 1937, 4(16):386-405.

2. Williamson, Oliver E . Transaction-Cost Economics: The Governance of Contractual Relations[J]. Journal of Law \& Economics, 1979, 22(2):233-261.

3. Gereffi G, Humphrey J, Sturgeon T. The governance of global value chains[J]. Review of International Political Economy, 2005, 12(1):78-104.

4. Williamson O E. OUTSOURCING:

TRANSACTION COST ECONOMICS AND

SUPPLY CHAIN MANAGEMENT*[J]. Journal of Supply Chain Management, 2008, 44(2).

5. Sanchez R, Mahoney J T . Modularity, flexibility, and knowledge management in product and organization design[J]. Strategic Management Journal, 2015, 17(S2):63-76.

6. Dong $\mathrm{Wu}$. Practical research on financial audit in enterprise internal control $[\mathrm{J}]$. China business theory, 2019 (18): 171-172

7. Maojian Yu, Yuanxin Sun. Game Analysis of specific investment governance mode selection based on relational contract $[\mathrm{J}]$. Operations research and management, 2020,29 (11): 45-52 